\title{
Basic Academic Research Structure and Format Guiding Principles for Stud $\underset{\equiv}{\equiv}$ s
}

\author{
Aquila Hakim M. Jongroor \\ School of Public Health, Texila American University, Guyana, South America
}

\begin{abstract}
The main purpose of the guideline is to develop a basic academic research structure and format guiding principles for students with two specific objectives; to develop a coherent research structure and academic research format for the public universities in South Sudan. One hundred and seventeen dissertations were reviewed, and a total of 88 teaching staff were interviewed, giving $91 \%$ response rate. The dissertations were selected randomly, and teaching staff were selected purposively by virtue of their positions and availability. The validity and reliability of the instruments was ensured through pretesting, CVI, and triangulations. SPSS $v 22$ was used to analyze data, both descriptive and thematic analysis were used. Permissions were sought from university administrations and one of the respondents before data collection. There is some significant variation on academic structure and format across the five universities in the republic of South Sudan. The research structural variations and inconsistencies were found in their contents and order of titles and subtitles of dissertations reviewed. In conclusion, this basic academic research guide is developed to set some standards and directions for students and their supervisors to complete the dissertation on time with less stress as it provides where to begin and the end. It will also enhance the objective grading of dissertations and evaluation levels of the university. The guideline will contribute to the development of consensus on academic research structure and format standards for students that will encourage young researchers to have an interest in research as a career.
\end{abstract}

Keywords: Basic academic research structure, Format guide.

\section{Introduction}

South Sudan is the newest country in the African Continent which got its independent in one decade ago on $9^{\text {th }}$ July 2011 from Sudan with a population of about 13 million [1]. The Country current has five public universities, namely the University of Juba, Bhar El Gazal University, Upper Nile University, Rubek University of Science and Technology, and Dr. John Garang Memorial of Science and Technology.

This study is one the first of its kind after the independent as part of efforts to improve the higher learning system in general and academic research quality in particular. The research focused on research structure and its format as the basic guiding principle for university students and researchers [2]. Learning to become a researcher is a process that requires step-bystep practice, which must start from basic research structure to complex one. Students need some basic standards to build a foundation for conducting research for academic purposes as a learning experience before endeavoring to real live experience research for decision making [3].

The fundamental expects of academic research are structure and format. A clearly written academic research guideline helps students and their supervisors to conduct 
research with a yardstick and a common understanding of the expected outcome [4]. The academic research structure and format layout and entails the beginning and the end of the academic research in a logically manner with sense of coherence of all its parts [5]. Writing an academic research is unique, and it is not the same as writing sermons, compositions, or a one-man write-up [6].

Academic research formatting provides consistency, user-friendly readability, focus on content, and facilitates the practice of discipline and adherence to the standards. It is the responsibility of an individual university to guide research formatting to determine font type/size, margins, pagination, among others [7].

Research format is important in academic writing because it helps to make your ideas clear, guides the reader's comprehension, and can strengthen a researcher argument [8]. Academic research structure helps in the development of ideas, skills and motivates students to identify their career path. When conducting research is made simple, the students become very interesting in research and will acquire necessary skills and knowledge that promote independence, collaboration, and innovations, which contribute to the production of new knowledge of which the society and university can benefit [9].

Basic structure of a typical dissertation or thesis contents and their sequence broadly include preliminary pages, body, and annexes. Preliminary pages contents sequentially start with cover page, inside title page, approval, declaration, dedication, acknowledgement, table of contents, list of table, list of figures, list of abbreviations and acronyms, and abstracts. Academic research body consist of section one, section two, section three, section four, and section five. The sections are titled as follows introduction 1 , literature review 2 , methodology 3 , research findings 4 , discussion, conclusion, and recommendations [10].

There is no one standard academic research structure and format across the universities globally. The inconsistencies are seen in the contents and sequence of subtitles of dissertations. On the other hands, dissertation formats are determined by referencing style adopted by the university. The African content and regional universities are not exceptional. The five public universities in South Sudan are the worst when it comes to academic research structure and format. Content and order of dissertations are not consistent between and within the universities [11-15].

The double standard research structure and format is the source of confusing, disorganization resulting to frustration and discouragement of students to become research. In the absent of researchers and competent enough in South Sudan will have a negative impact in the wellbeing of the humanity at all aspects of live [16].

The main aim of this guideline is to develop a basic academic research structure and format for students with two specific objectives; to develop a coherent research structure and academic research format. The public in Universities of the Republic of South Sudan do not consistent research structure.

This article attempted to provide a basic standard and coherent academic research structure and format for students to complete the dissertation within the time frame without frustration which can be evaluated in an objective manner. The guideline be used as a reference for the development of research policies, guidelines, and dissertation supervision, and marking guide as well.

\section{Methods and Materials}

This research adapted qualitative and quantitative approach, descriptive and crosssectional designs to assess research structure and format in five public universities in the Republic of South Sudan. Dissertations of the students in University of Juba, Upper Nile University, Bhar El Gazal University, Rumbek University, and Dr. John Garang Memorial University of Science and Technology were the target objects 
and teaching staff of the same universities. Both qualitative and quantitative approaches are useful triangulation of data [17]. Description of the existing research structure and format can be well-articulated using a descriptive design, which has the ability of providing in-depth information for a better understanding of the variables [18]. The cross-sectional design has no time dimension. This design was preferred as the information was collected from dissertations and teaching staff of the universities as they exist at the point in time. The research paradigm is epistemology because of the objectivity and subjectivity of the research design [19]. The sample size was determined proportionately based on the number of dissertations and teaching staff. A total of 225 participants and objects were participated in soliciting data. These include 25, 75, and 125 head of departments or Deans of faculties, teaching staff (Lecturers, teaching assistants etc.), and 225 dissertations, respectively [20].

Primary and secondary constituted the data source for this study. Primary data were collected from 100 teaching staff and secondary data from dissertations. Dissertations were selected randomly, while teaching staff were selected purposively by virtue of their positions and availability [21]. All participants consented verbally before they provide information. Permissions were sought from each university before accessing dissertations, policies, and guidelines from libraries.
Observation checklist, questionnaires, and interview guides were used to collect both quantitative and qualitative data. Validity and reliability of the data collection tools were ensured by pre-testing the tools, content validity index was used, and triangulation of the data collection instruments were the techniques used [22]. Descriptive analysis was used to run the frequencies for quantitative data using SPSS v21 and qualitative data was analyzed using thematic analysis [23].

This study is subjected to methodological, contents, and context limitations, these include but not limited to cross-sectional design does encounter casualty limitations, some degree of selection bias, recalled bias, social desirability bias, and scarcity of academic materials [24].

\section{Results}

All five public universities were included in the study, and Table 1 below depicts distributions of objects and participants. The number of respondents was determined proportionately.

There is significant variation in the contents and sequence of the academic research structure in the five public universities of the Republic of South Sudan. However, the major sections are consistent that's preliminary pages, research body, and appendixes. Research paper formatting generally is more consistent compared to the structure. Some of the notable disparities are seen in the cover page color of dissertations.

Table 1. Distribution of Participants and Objects by Public Universities

\begin{tabular}{|l|l|l|l|}
\hline Name of University & \% of Teaching staff & \% of Dissertations reviewed & Total \% \\
\hline University of Juba & $51 \%$ & $36 \%$ & $43.5 \%$ \\
\hline Bhar El Gazal University & $18 \%$ & $23 \%$ & $21.5 \%$ \\
\hline Upper Nile Univeristy & $15 \%$ & $17 \%$ & $16 \%$ \\
\hline Rumbek University & $10 \%$ & $13 \%$ & $11.5 \%$ \\
\hline Dr. John Garang University & $6 \%$ & $11 \%$ & $8.5 \%$ \\
\hline Total & $\mathbf{1 0 0 \%}$ & $\mathbf{1 0 0 \%}$ & $\mathbf{1 0 0 \%}$ \\
\hline
\end{tabular}




\section{Academic Research Structure}

The major variations and inconsistencies of academic research structure in the public universities in South Sudan were found to be in the contents and order of titles and subtitles.
The main contents of the preliminary pages were fairly well presented in the dissertations. However, there were notable inconsistencies in the order of the contents of the preliminary pages Figure. 1.

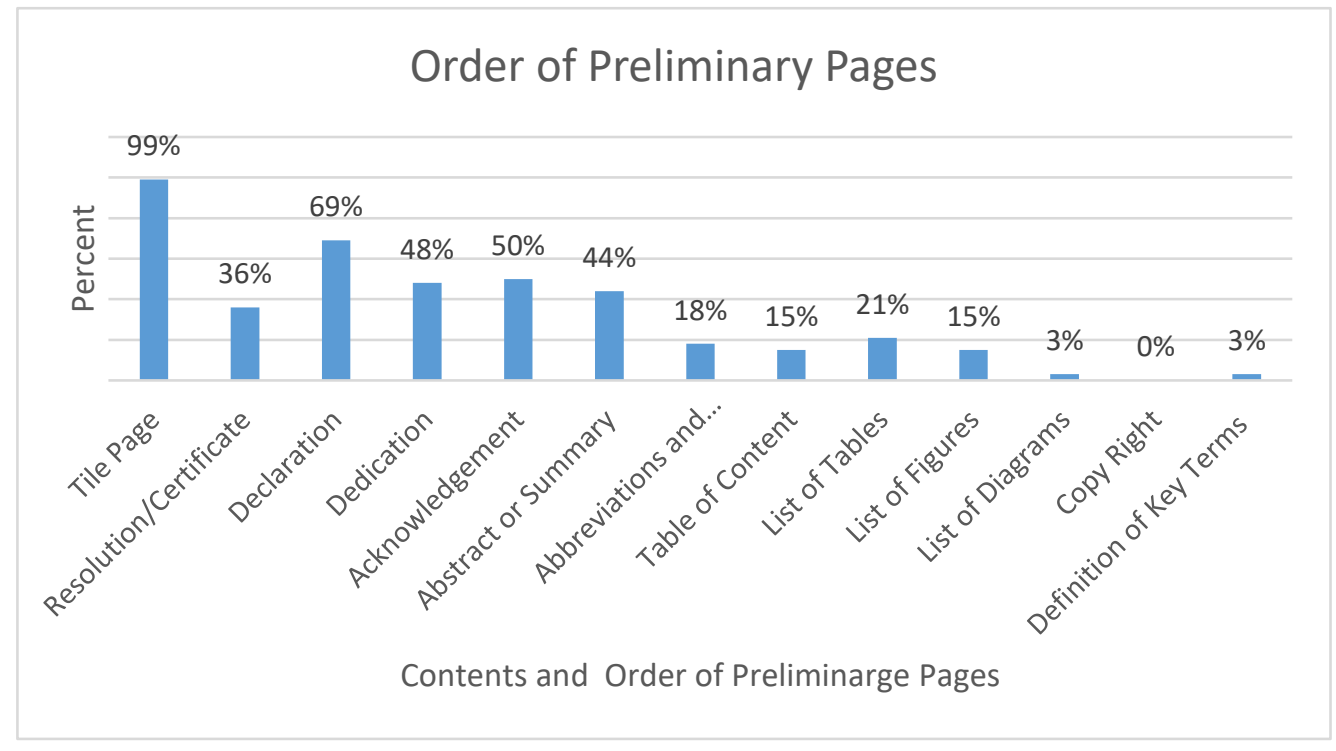

Figure 1. Order of Preliminary Pages Contents

The availability of the main sections in the dissertations written by students in the five public universities was observed using observation checklist. Figure 2 below shows the distribution. Only $50 \%$ of dissertations reviewed have references and appendixes. Majority of dissertations have five sections only.

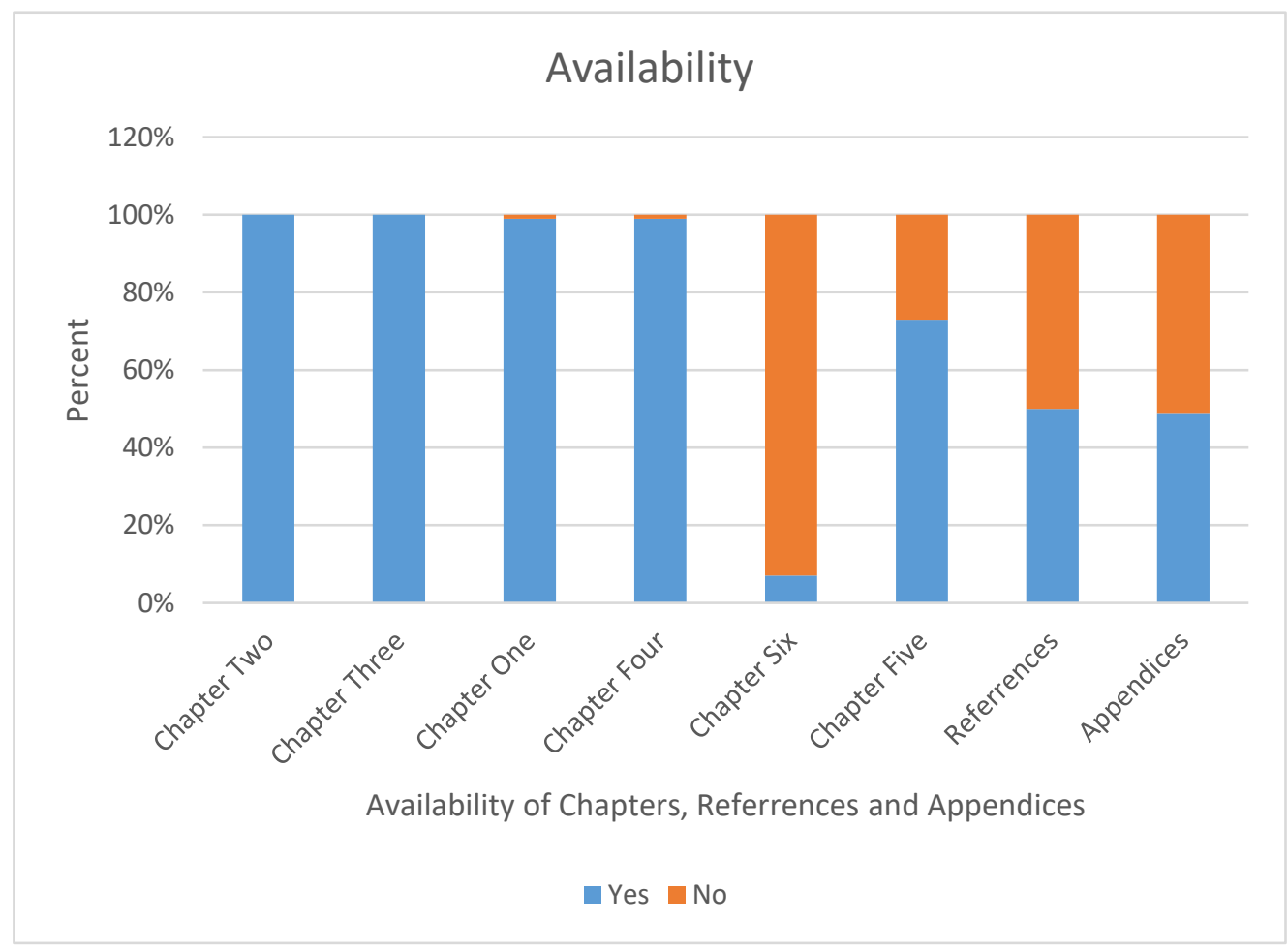

Figure 2. Availability of the Main Sections in the Dissertations 
There are different titles used for the main headings of the body of the academic research. Section one the following headings were used to represent the Section. Introduction and background $38 \%$, introduction $38 \%$, literature review $14 \%$, background $3 \%$ and other titles used $7 \%$. Section two headings were literature review $74 \%$, methods and materials $15 \%$, theoretical framework 3\%, conceptual framework 2\%, and 7\% for others. Section three headings only $28 \%$ and $22 \%$ of dissertations wrote research methodology and methodology respectively as titles for the section. The remaining $50 \%$ of dissertations reviewed missed the right heading. The following are some of the headings used by the students instead to represent section three heading; results $21 \%$, designs 9\%, methods, and materials $7 \%$, procedure $7 \%$, and methods $6 \%$. About 50 different titles were used by students to represent section four in the dissertations. The two most frequent titles were data results and discussion $21 \%$ and result $10 \%$. The other 45 titles constitute $69 \%$, with an average of $2 \%$ each. Surprisingly $22 \%$ of dissertations did not have section five. One of the common title used was summary and conclusion $31 \%$ as the title for section five. The other titles were summary and findings $6 \%$, recommendations $5 \%$, discussions $3 \%$, and $32 \%$ others.

The below basic academic research structure is developed based on the findings and literature to be used by students and their supervisors as a guiding principle [24].

Figure 3 illustrates the structure of academic research showing major sections, titles, subtitles, and their sequential order from top to bottom.
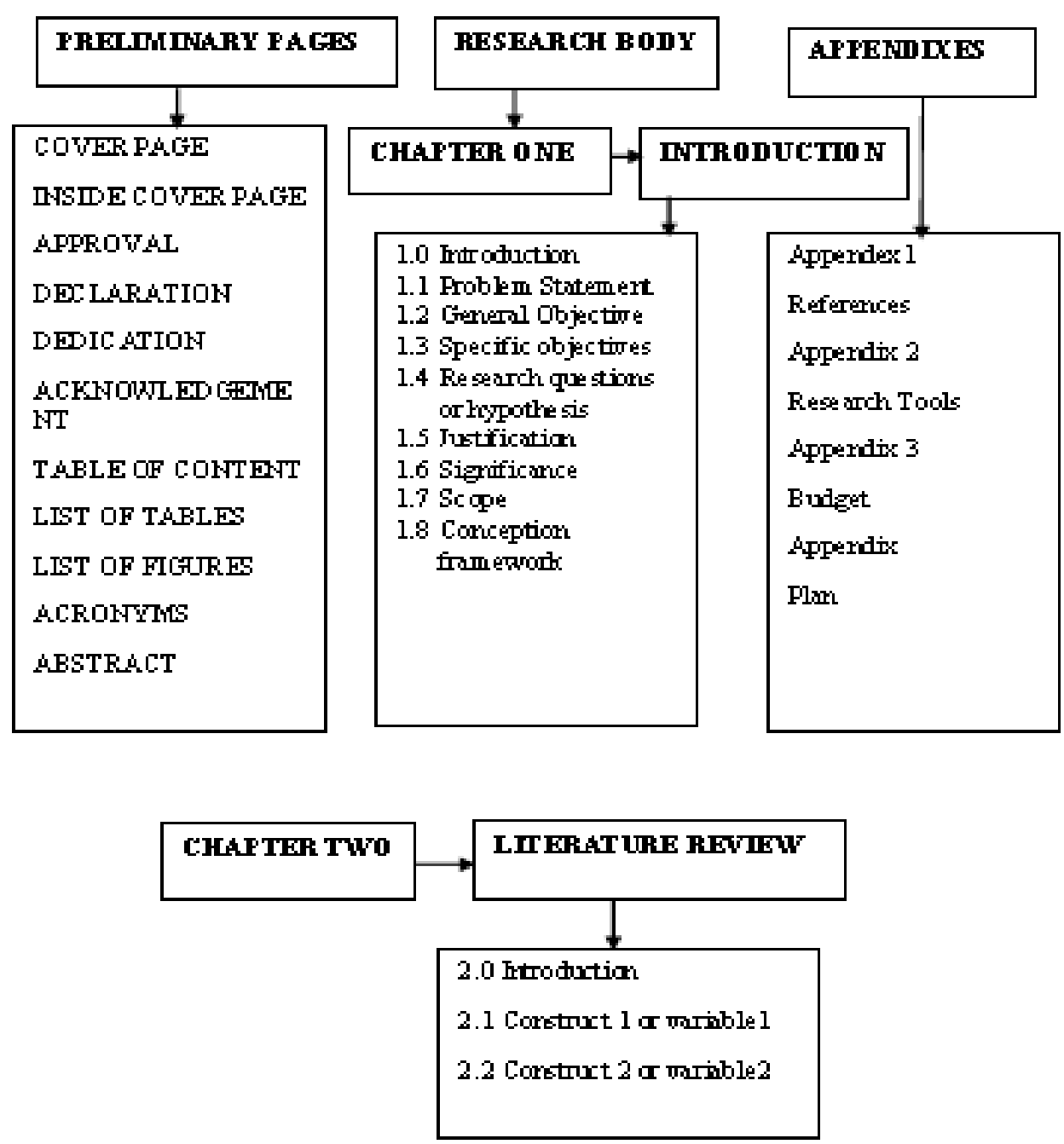

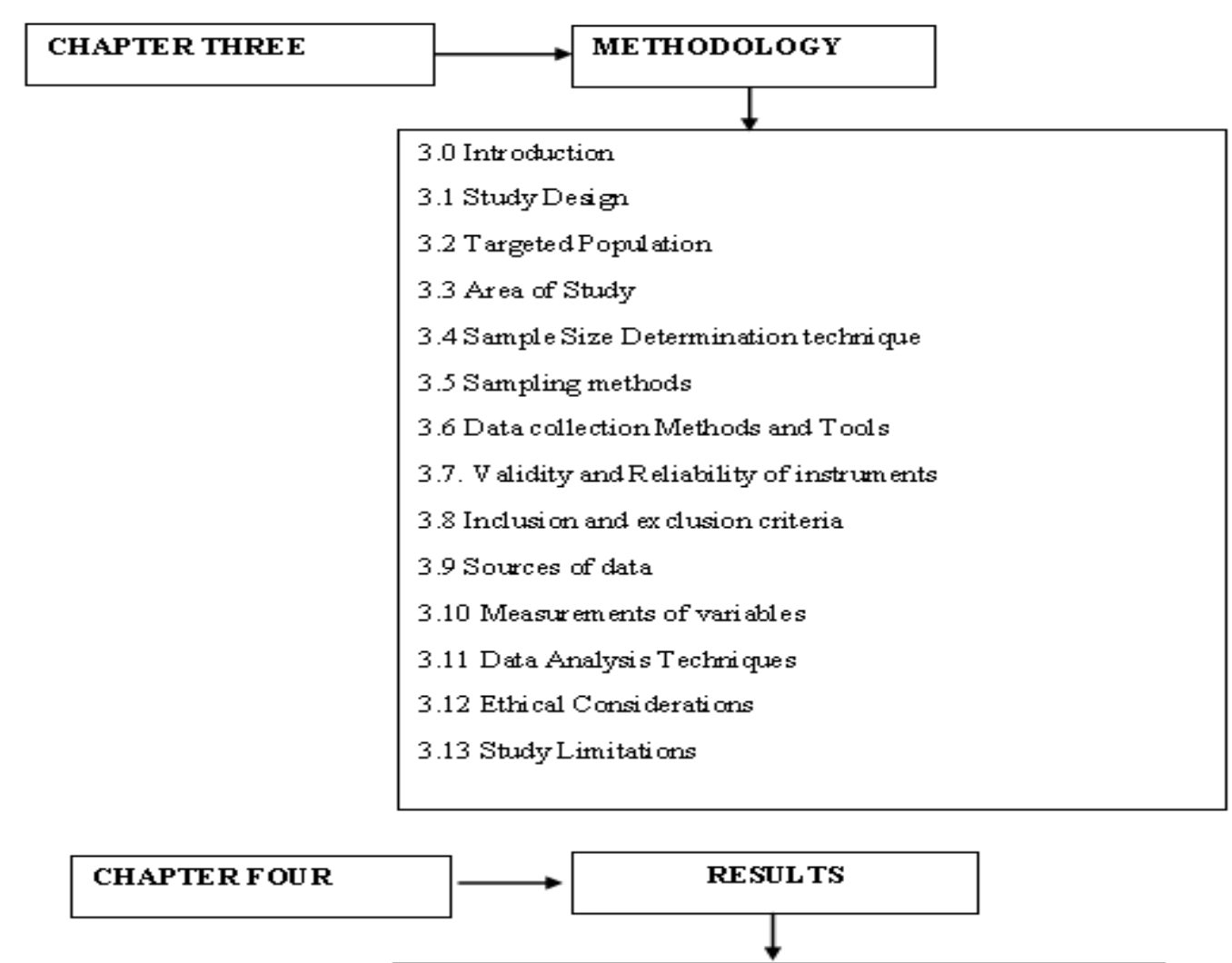

4.0 Introchuction

4.1 Response Rate

4.2 Demographic Characteristics

4.3 Objective one title

4.3.1 Subtitle e.g. Attribute

4.40 bjective two title

\section{CHAPTER YIVE}

\section{DISCUSSION, CONCLUSION AND REC OMMENDATIONS}

5.0 hitroduction

5.1 Dious findings

52 Concharian

53 Recamendition

\subsection{Sucented are a f further Re warch}

Figure 3. Basic Academic Research Structure

Table 2 depicted the recommended subheadings and order of preliminary pages. The variations were in order rather than the content. Table 3 propose the length of a research paper be 
estimating the number of pages for each title and subtitle as a guide.

Body of the Research is the largest part of the research paper. It consists of five sections that constitute a dissertation.

Appendixes are some parts of a dissertation that cannot be included in the main text. Table 4 shows some of the most common parts of an appendix in academic research.

\section{Academic Research Format}

The research paper format is largely determined by referencing style adapted by the university. However, some of the most common referencing styles, such as the American Psychological Association, AMA, Harvar, Chicago etc., use almost the same formatting with very minimal discrepancies. Table 4 depicted research format standards [25].

Table 2. Order and Contents of the Preliminary Pages

\begin{tabular}{|l|l|l|l|}
\hline Sections & Recommended Headings & Contents and their Order & Number of Pages \\
\hline \multirow{5}{*}{ None } & \multirow{4}{*}{$\begin{array}{l}\text { Initial Pages do not have a } \\
\text { Section }\end{array}$} & Title & 1 page \\
\cline { 3 - 4 } & & Approval & 1 page \\
\cline { 3 - 4 } & Declaration & 1 page \\
\cline { 3 - 4 } & Dedication (Optional) & 1 Page \\
\cline { 3 - 4 } & Acknowledgement & 1 page \\
\cline { 3 - 4 } & Table of content & Depend \\
\cline { 3 - 4 } & List of Tables & Depend \\
\cline { 3 - 4 } & List of Figures & Depend \\
\cline { 3 - 4 } & List of Equations (Optional) & Depend \\
\cline { 3 - 4 } & Abbreviations & Depend \\
\cline { 3 - 4 } & Abstract & 1 page \\
\hline
\end{tabular}

Table 3. Contents and Order of Research Body

\begin{tabular}{|c|c|c|c|}
\hline Sections & Recommended Headings & Contents and their Order & Number of Pages \\
\hline \multirow{8}{*}{ Section One } & \multirow{8}{*}{ Introduction } & Introduction & 1 - 2 Pages \\
\hline & & Statement of the Problem & \multirow{7}{*}{$2-4$ pages } \\
\hline & & Broad Objective & \\
\hline & & Specific Objectives & \\
\hline & & Research Question or Hypothesis & \\
\hline & & Justification & \\
\hline & & Scope & \\
\hline & & $\begin{array}{l}\text { Conceptual or Theoretical } \\
\text { Framework }\end{array}$ & \\
\hline \multirow[b]{2}{*}{ Section two } & \multirow[b]{2}{*}{ Literature Review } & Introduction & \multirow[b]{2}{*}{$3-6$ pages } \\
\hline & & $\begin{array}{l}\text { By objectives and variables or } \\
\text { Constructs and Attributes }\end{array}$ & \\
\hline \multirow{7}{*}{ Section Three } & \multirow{7}{*}{ Methodology } & Research Designs and approaches & \multirow{7}{*}{$3-6$ Pages } \\
\hline & & Study targeted Population & \\
\hline & & Study area & \\
\hline & & Sample Size Determination & \\
\hline & & Sampling methods and techniques & \\
\hline & & Inclusion and Exclusion Criterion & \\
\hline & & Ethical Considerations & \\
\hline
\end{tabular}




\begin{tabular}{|c|c|c|c|}
\hline & & Data Sources & \\
\hline & & Measurement of variables & \\
\hline & & Data Analysis techniques & \\
\hline & & $\begin{array}{l}\text { Research Limitations and } \\
\text { Delimitations }\end{array}$ & \\
\hline \multirow{4}{*}{ Section Four } & \multirow{4}{*}{$\begin{array}{l}\text { Research Finding and } \\
\text { Interpretation }\end{array}$} & Introduction & \\
\hline & & Response Rate (Optional) & \\
\hline & & $\begin{array}{l}\text { Demographic Characteristics } \\
\text { (Optional }\end{array}$ & \\
\hline & & $\begin{array}{l}\text { By objectives and variables or } \\
\text { Constructs and Attributes }\end{array}$ & 6 - 10 Pages \\
\hline \multirow{4}{*}{ Section Five } & \multirow{4}{*}{$\begin{array}{l}\text { Discussion, Conclusion } \\
\text { and Recommendations }\end{array}$} & Introduction & \multirow{4}{*}{ Max 3 pages } \\
\hline & & Conclusion & \\
\hline & & Recommendations & \\
\hline & & Further Research & \\
\hline
\end{tabular}

Sources of data: Primary and Makerere University 2011 [26].

Table 4. Order and contents of the Appendixes

\begin{tabular}{|c|c|c|c|c|}
\hline Major Categories & Sections & Recommended Headings & Contents and their Order & Number of Pages \\
\hline \multirow{7}{*}{ (3) Appendixes } & Appendix 1 & List of Referrences & $\begin{array}{l}\text { Complete references } \\
\text { using APA or Harvard } \\
\text { Referencing style }\end{array}$ & Depend \\
\hline & \multirow{3}{*}{ Appendix 2} & \multirow{3}{*}{ Recommended Tools } & $\begin{array}{l}\text { Questionnaires } \\
\text { (Optional) }\end{array}$ & Depend \\
\hline & & & $\begin{array}{l}\text { Interview Guide } \\
\text { (Optional) }\end{array}$ & 1 Page \\
\hline & & & $\begin{array}{l}\text { Observation Checklist } \\
\text { (Optional) }\end{array}$ & Depend \\
\hline & Appendix 3 & \multirow{3}{*}{$\begin{array}{l}\text { Plus, others not limited } \\
\text { to these items }\end{array}$} & Plan & 1 Page \\
\hline & Appendix 4 & & Budget & 1 Page \\
\hline & Appendix 5 & & Map (Optional) & 1 Page \\
\hline
\end{tabular}

Table 5. Academic Research Format

\begin{tabular}{|l|l|l|}
\hline Components & APA & Harvard \\
\hline Font type & Time New Roman & Time New Roman \\
\hline Font size & $11-12$ points size & $10-12$ Points size \\
\hline Font color & black & black \\
\hline Page size & & $8.5-11$ inch \\
\hline Page margins & 2inch top & 1 inch \\
\hline Top margin & 50 & 1 inch \\
\hline Bottom margin & 25 & 1 inch \\
\hline Both sides margins & Left 50 & 1 inch \\
\cline { 2 - 3 } & Right 25 & \\
\hline Spacing & double & double \\
\hline Line space & 1.5 & 2 \\
\hline
\end{tabular}




\begin{tabular}{|l|l|l|}
\hline Alignment & justified & justified \\
\hline $\begin{array}{l}\text { Preliminary pages } \\
\text { Research body }\end{array}$ & Roman numbers & Roman numbers \\
\cline { 2 - 3 } Page size & Arabic numeral & Arabic numeral \\
\hline Page \# position & A4 & \\
\hline How to print & One side & $\begin{array}{l}\text { Top or bottom } \\
\text { centered }\end{array}$ \\
\hline
\end{tabular}

Source: Primary data, Emma [27] and Harvard University.

\section{Discussion}

\section{Academic Research Structure}

The major sections of the academic research include Preliminary Pages, body, and appendixes. These main categories are the same for all universities globally.

Preliminary pages also differ much in the contents, however, the sequence of the contents vary significant. Here are the most common contents and their sequential order. Cover page, inside title page, approval, declaration, dedication, acknowledgement, list of contents, list of table, list of figures, abbreviations, and abstract [20].

The body of academic research consists of five main sections, and these are 1 introduction, 2 literature review, 3 methodology, 4 results, and 5 discussion, conclusion, and recommendations. Though there are some variations in the titles of the main sections, but the sequence is the same largely.

The basic contents of section one and their order are the introduction, problem statement, general objective, specific objectives, research questions or hypothesis, justification, significance, scope, and conception framework or theoretical frame.

Methodology describes section three perfectly compared to the other titles being used for the same section. This section may have many contents depending on the type of research. However, the following generic contents and order provide guiding principles for students. Research design (s), population, area of study, sample size determination, sampling methods, data collection techniques, sources of data, inclusion and exclusion criteria, validity and reliability of data collection tools, measurements of variables, data analysis techniques, ethical considerations, and limitations.

For simplicity and consistency, section four title is results, and the subtitle should be based on the objectives/attributes/variables after demographic characteristics of the respondents. The students in the public universities in the Republic of South Sudan use more than ten different titles for section four. These findings are also seen from Nairobi, Harvard, Makerere universities [22].

Discussion, conclusion, and recommendations constitutes section four, though other universities or faculties divide the section into section five and six, where discussion becomes section five and section six takes conclusion and recommendations.

The appendix is the last part of academic research that could contain any other part of research that cannot be included in the main text. Appendix should include references, data collection tools, plan, and budget.

\section{Academic Research Format}

Format of the academic research is largely determined by the referencing style adopted by the university or faculty. The format covers wide range of font, spacing, margins, pagination, paper, printing, and book color.

Research is preferred to be writing clearly and avoiding fancy styles at all form. The acceptable and recommended format are that one of APA, Harvard, etc. referencing style [23].

Type of font should be new time roman and font size 11 - 12-point size and text of a research body justified. The first level heading font 
should be 14-inch, second level 13 inch, and third level 12 inch. First-level heading capitalized and centered. Second level subheading aligned left with the first letter of each word capitalized, the same to third-level subheadings.

This is the most common, less complicated academic research format and promotes the readability of the text [24].

\section{Conclusion}

In conclusion, this basic academic research guide will give direction to students and their supervisors to complete the dissertation on time with less stress as it provides where to begin and the end. It also enhances objective grading of dissertations and evaluation level of the university. The guideline will contribute to the development of consensus on academic research structure and format standards for students that will encourage young researchers to have an interest in research as a career.

\section{References}

[1] National Bureau of Statistics 2021. South Sudan Population projection. Official circular for planning purpose.

[2] University of Michigan. Dissertation format guidelines. Rakham graduate school student services: academic records \& dissertation. www.rackham.umich.edu accessed on $3^{\text {rd }}$ November 2021.

[3] Alf Gunvald Nilsen 2019. What is Academic Writing? Structure in Academic Writing. Sociology Postgraduate Writing Seminar. PP 5.

[4] Baxis I. Patel 2019. Format and Contents of Academic Research Project report. Department of Commerce and Business Management, the Maharaja Sayajirao University of Baroda, Vadodara. Gujarat PP 4.

[5] Isabel Gómez, María Bordons, M. Teresa Fernández, Fernanda Morillo (2009). Structure and research performance of Spanish universities. Akadémiai Kiadó, Budapest Scientometrics, Vol. 79,

\section{Acknowledgement}

I would like to extend my sincere gratitude to my Co-guide Professor, Dr. Akway Cham, for his guidance from the beginning to the end of academic research work. Without underestimating the support provided by Dr. Joseph virtually as the university guide.

My joy and appreciation goes to Ms. Jesna, my long-serving mentor, for her immense encouragement and motivation for me to be on top of my academic assignments.

Omar Yaya is my senior colleague who encouraged me to do a Ph.D. in Public health with the Texila American University distance learning program three years ago.

Finally, I would like to thank my family for their moral supports and encouragement to study at this difficult time.

\section{Conflict of Interest}

I, Aquila Hakim M. Jongroor, declare there is no conflict of interest in all forms.

No. 1 (2009) 131-146 and Springer, Dordrecht DOI: 10.1007/s11192-009-0408-0.

[6] Dare E. Ajayi 2012. Foundational Guide to Research, Thesis and Dissertation Writing. A Practical Approach. PP 3 - 4 LIVING Peace Publication. ISBN: 978-978-50845-2-8 Federal Republic of Nigeria.

[7] Kenyatta University 2013. Guideline for Writing Academic Research Proposals and Theses in the School of Education.

[8] Thamara Fudge 2019. The Importance of Formatting. Purdue Global Academic Success Writing Center. School of Business and IT, Kaplan University PP 10.

[9] John K. Petrella and Alan P. Jung (2008). Undergraduate Research: Importance, Benefits, and Challenges. PP 1 Samford University, Birmingham, Alabama, USA.

[10] Ranjit Kumar 2021. Research Methodology. A step-by-step guide for beginners. SAGE Publications Ltd 1 Oliver's Yard 55 City Road London EC1Y 1SP. ISBN 978-1-84920-300-5. 
[11] Harvard University 2020. Harvard Formatting and Style Guide.

[12] University of Technology Sydney (2017). Research Proposal Writing. ELSSA Center: UTS. Accessed on 22 March 2020.

[13] Uganda Management Institute - UMI (2012). Research Methods module 1. Distance Learning Department.

[14] University of Nairobi 2021. Guidelines for Project Paper Thesis Proposal Writing. Faculty of Arts Postgraduates Studies Committee.

[15] Onen D. 2014, How to Write a Successful Doctoral Research Proposal: The Makerere Format. EASHESD, College of Education \& External Studies, Makerere University. P 3.

[16] John W. Creswell and J. David Creswell 2017 Research Design: Qualitative, quantitative, and mixed methods Approaches https://edge.sagepub.com/creswellrd5e.

[17] Andrew P. Johnson 2012. Short Guide to Action Research $4^{\text {th }}$ edition. Science Research and Teaching. Minnesota State University, Mankato.

[18] Muhammad Mahboob Ali and Kamrul Hossain (2016). Instruction Manual: Research Methodology Volume: 2 Institutional Quality Assurance Cell, Daffodil International University. ISBN: 978-98434-1757-2.

[19] Kjell E. R. and Rae R. N. 2017, Surviving Your Dissertation: A comprehensive guide to content and process $3^{\text {rd }}$ ed. P 90 - 94. Sage Publications, Inc. ISBN 978-4129-1678-3.

[20] Patino, C. M., \& Ferreira, J. C. 2018. Inclusion and exclusion criteria in research studies: definitions and why they matter. Jornal brasileiro de pneumologia: publicacao oficial da Sociedade Brasileira de Pneumologia e Tisilogia, 44(2), 84. https://doi.org/10.1590/s1806-37562018000000088.
[21] Hamed T. 2016, Validity and Reliability of the Research Instrument; How to Test the Validation of a uestionnaire/Survey in a Research. The University of Canada West. SSRN Electronic Journal 5(3):28-36 DOI:10.2139/ssrn.3205040.

[22] Siegmund B. 1998, Data Analysis Siegmund Brandt Statistical and Computational Methods for Scientists and Engineers $4^{\text {th }}$ ed, Department of Physics University of Siegen Siegen, Germany. Cham Heidelberg New York Dordrecht London. ISBN 978-3-319-03761-5 ISBN 978-3-319-03762-2 (eBook) DOI 10.1007/978-3-319-03762-2.

[23] Nilesh G. 2013, Ethical Consideration in Research. / International Journal for Research in Education Vol. 2, Issue:7.

[24] Benard Muma 2020. Basic Structured Guide for Writing Academic Research. Department of Management Science and Technology. The Technical University of Kenya. PP 1 -10.

[25] Dli, Unilag, Fednet. Research Project Format for All Students. www.fednetnigeria.wordpress.com [26] Makerere University 2011. Guidelines for Formatting Research Proposals, Research Reports, Thesis and Dissertations. Directorate of Graduate and Training PP $5-6$.

[27]Emma Geller How to Write APA Style Research Papers

http://www.psychology.ucsd.edu/undergraduateprogram/academic-writing-resources/ Arranged by S.C. Pan for UCSD Psychology accessed on $3^{\text {rd }}$ November 2021. 